\title{
Pengaruh Pupuk N dan Cekaman Kekeringan terhadap Pertumbuhan dan Kandungan Artemisinin Tanaman Artemisia vulgaris $\mathbf{L}$.
}

\author{
Effect of Nitrogen Fertilizer and Stress Water on The Growth and \\ Artemisinin Content of Artemisia vulgaris $\mathbf{L}$.
}

\author{
Elvina Sari*, Zozy Aneloi Noli, Suwirmen \\ Laboratorium Fisiologi Tumbuhan, Jurusan Biologi, FMIPA Universitas Andalas, Kampus Unand \\ Limau Kampus Unand Limau Manis Padang - 25163 \\ Koresponden* : elvinasari1110423049bio@gmail.com
}

\begin{abstract}
The research about effect of Nitrogen fertilizer and stress water on the growth and artemisinin content of Artemisia vulgaris L. has been conducted from December 2015 to March 2016 in Screen House and Plant Physiology Laboratory, Department of Biology, Faculty of Mathematics and Natural Science, Andalas University, Padang. The purpose of this research were to the effect of Nitrogen fertilizer, stress water, and their interaction between on the growth and artemisinin content of A. vulgaris. This research used Completely Randomized Design (CRD) in factorial with four treatments ad three replications. The result showed that the number of leaves, plant height, length of roots, fresh weight, dry weight and of Artemisia vulgaris L. were increased significantly on $\mathrm{N}$ fertilizer treatments. The treatment of stress water $60 \%$ of volume capacity gave significantly effect on numbers of leaves and the highest content of Artemisinin was $80 \%$ volume capacity. The interaction of $\mathrm{N}$ fertilizer and stress water did not showed significantly effect on the growth and artemisinin content of Artemisia vulgaris L.
\end{abstract}

Keywords : artemesinin content, nitrogen fertilizer, stress water

\section{Pendahuluan}

Artemisia merupakan tanaman obat yang berasal dari famili Asteraceae yang sudah lama digunakan di Cina sebagai obat anti malaria (Klayman, 1985). Pil kina yang selama ini menjadi obat andalan untuk mengatasi penyakit malaria ini telah resisten terhadap Plasmodium falciparum, sehingga diupayakan untuk mencari alternatif tanaman lain yang mampu untuk mengatasi penyakit tersebut. Penelitian mengenai hal ini telah dilakukan dan hasil dari penelitian tersebut merekomendasikan tanaman Artemisia sebagai tanaman obat untuk mengatasi penyakit malaria secara efektif.

Salah satu alternatif tanaman yang digunakan adalah tanaman Artemisia vulgaris (WHO, 2004). Saat ini tanaman obat yang digunakan sebagai obat malaria adalah $A$. annua, namun tanaman ini merupakan tanaman subtropis sehingga tidak sesuai apabila dibudidayakan di daerah tropis. Meskipun demikian terdapat jenis Artemisia lain yang tumbuh di daerah tropis Indonesia seperti Artemisia vulgaris. A. vulgaris merupakan tanaman yang dapat hidup pada ketinggian 1000-1500 mdpl dan juga mengandung senyawa artemisinin (Judzentiene dan Buzelyte, 2006). ketersediaan unsur hara di berbagai tempat berbeda-beda. Untuk menunjang pertumbuhan tanaman, diperlukan pemasukan unsur hara dari luar seperti pemberian pupuk. Menurut Gusmaini dan Nurhayati (2007), pemupukan berperan penting dalam produksi biomassa tanaman. Menurut Sirait (2007), 
salah satu upaya untuk meningkatkan perkembangan pada pertumbuhan yaitu dengan pemberian pupuk nitrogen $(\mathrm{N})$. Hal ini dikarenakan nitrogen biasanya memberikan pengaruh nyata terhadap pertumbuhan vegetatif dan reproduktif tanaman.

Penelitian mengenai aplikasi pupuk nitrogen telah dilakukan oleh Hendra et al., (2014) mengenai aplikasi kompos ganggang cokelat (Sargassum polycystum) yang diperkaya pupuk N, P, K terhadap inseptisol dan jagung hasil yang didapatkan dari penelitian tersebut yaitu pada dosis urea 2 g/polibag memberikan pengaruh terhadap pertumbuhan tanaman yaitu meningkatkan fase awal vegetatif seperti tinggi tanaman dan berpengaruh nyata terhadap berat kering tanaman. Pada penelitian yang dilakukan oleh Yudi et al., (2016) mengenai pertumbuhan dan hasil bawang daun (Allium fistulosum L.) varietas linda akibat pemberian pupuk kandang ayam dan pupuk urea menunjukkan pengaruh pada pemberian pupuk urea $1.6 \mathrm{~g}$ urea terhadap pertumbuhan tinggi tanaman, jumlah anakan dan hasil pertanaman bawang daun varietas linda.

Mengingat masih sedikitnya kandungan artemisinin pada tanaman $A$. vulgaris maka perlu dicari alternatif untuk meningkatkan kandungannya. Salah satu alternatif yang digunakan yaitu dengan pemberian cekaman. Menurut Salisbury dan Ross (1995) cekaman biologis terhadap tumbuhan menyebabkan stres yang meningkatkan produksi metabolit sekunder, cekaman lingkungan dapat digunakan sebagai strategi untuk mengoptimalkan produksi senyawa tertentu pada tanaman.

Ketersediaan air merupakan salah satu faktor yang dapat menimbulkan cekaman pada tanaman. Manipulasi cekaman air terbukti mampu meningkatkan kandungan metabolit sekunder pada beberapa tanaman. Rahardjo et al., (1999) mengkaji tentang pengaruh cekaman defisit air terhadap tanaman tempuyung (Sonchus arvensis). Cekaman air 60\% KL (kapasitas lapang) meningkatkan kandungan flavonoid daun tempuyung sebanyak 2,11\% dibanding kontrol. Menurut Trisilawati dan Pitono (2012), Pembentukan bahan aktif pada purwoceng (pimpinella pruatjan) didapatkan hasil bahwakan kandungan metabolit sekundernya meningkat seperti kandungan bahan aktif steroid, saponin dan bergapten pada cekaman air $60 \% \mathrm{KL}$.
Berdasarkan uraian diatas maka telah dilakukan penelitian dengan tujuan mengetahui pengaruh pemberian pupuk $\mathrm{N}$, cekaman air serta

interaksi antara pupuk nitrogen dan cekaman air terhadap pertumbuhan A. vulgaris dan kandungan artemisinin.

\section{Metode Penelitian}

Penelitian ini dilaksanakan pada bulan Desember 2015 sampai Maret 2016 di rumah kawat dan Laboratorium Fisiologi Tumbuhan Jurusan Biologi Fakultas Matematika dan Ilmu Pengetahuan Alam Universitas Andalas, dengan menggunakan metode Rancangan Acak Lengkap (RAL) dalam faktorial. Terdiri dari 4 faktor perlakuan dengan 3 kali ulangan. Faktor pertama pupuk urea dengan konsentrasi pupuk $(0,0.93,1,86,2,80 \mathrm{~N}$ g/polybag) dan faktor kedua cekaman air ( pemberian air 100, 80, 60, 40\% Kapasitas Lapang).

\section{Persiapan Media Tanam}

Media tanam yang digunakan adalah tanah kebun. Sebelum digunakan tanah dikeringkan dan dihaluskan. Tanah yang sudah dihaluskan kemudian diayak menggunakan ayakan. Tanah yang telah diayak ditimbang sebanyak $3 \mathrm{~kg}$ dan dimasukkan kedalam polybag ukuran $38 \mathrm{x}$ $35 \mathrm{~cm}$

\section{Penyedian Bibit}

Tanaman A. vulgaris yang digunakan untuk pembibitan koleksi di Padang Panjang, Sumatera Barat. Bibit yang digunakan dalam percobaan ini adalah hasil perbanyakan melalui stek pucuk dari tanaman A. vulgaris.

\section{Pemberian Perlakuan}

Pemberian perlakuan yaitu pupuk urea ditimbang sesuai dengan perlakuan yaitu 0 , $0,93,1,86,2,80 \mathrm{~N} \mathrm{~g} /$ polybag. Pupuk diberikan diawal penanaman kemudian tanaman juga diberi variasi ketersediaan air yaitu 100. 80, 60, $40 \%$ Kapasitas Lapang sesuai dengan metoda "Gravimetrik" (Kurnia U et.al. 2006)

\section{Parameter Pengamatan}

Pertambahan Jumlah Daun (helai) 
dan dilarutkan dengan heksan sebanyak 10 $\mathrm{mL}$, kemudian dishacker selama 10 menit, dipanaskan pada water bath dengan suhu $70^{\circ} \mathrm{C}$ selama 10 menit. Setelah selesai dikeluarkan dan diuapkan pada suhu ruang. Bagian yang tertinggal dilarutkan dengan asetonitril sebanyak $1 \mathrm{~mL}$ dan dimasukkan kedalam tabung Eppendorf, disentrifus untuk mengendapkan bagian daun yang terbawa dalam fasa cair Kemudian ekstrak dianalisis, fase gerak HPLC mengunakan asetonitril : air (60 : 40) $1,2 \mathrm{~mL}$ dengan panjang gelombang 216.

\section{Analisis Data}

Dari hasil pengamatan dianalisa secara statistik dengan sidik ragam, dimana jika nilai $\mathrm{F}$ hitung berbeda nyata atau besar dari $\mathrm{F}$ tabel, maka dilanjutkan dengan Duncan's New Multiple Range Test (DNMRT) pada taraf uji nyata $5 \%$.

\section{Hasil dan Pembahasan}

\section{Pertambahan Jumlah Daun}

Berdasarkan analisis statistik terhadap pertambahan jumlah daun tanaman $A$. vulgaris dengan pemberian pupuk $\mathrm{N}$ dan cekaman kekeringan selama 8 minggu pengamatan menunjukkan bahwa dosis pupuk $\mathrm{N}$ dan cekaman kekeringan memberikan pengaruh yang nyata terhadap jumlah daun sedangkan interaksinya tidak berbeda nyata. Data disajikan pada Tabel 1Tabel 1. Rata-rata jumlah daun tanaman Artemisia vulgaris $\mathrm{L}$. dengan pemberian pupuk $\mathrm{N}$ dan cekaman kekeringan diakhir pengamatan setelah 8 minggu masa tanaman. kering, digiling sampai halus menggunakan
mesin penggiling. Ditimbang sebanyak 1 gram

Kadar artemisinin diukur dengan HPLC (High Performance Liquid Chromatography). Ekstrak dibuat dari daun tanaman yang telah

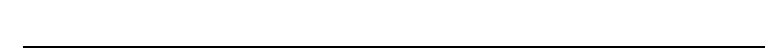

\begin{tabular}{|c|c|c|c|c|c|}
\hline \multirow{2}{*}{ Pupuk N } & \multicolumn{4}{|c|}{ Cekaman kekeringan $(\%)$} & \multirow{2}{*}{$\begin{array}{l}\text { Rata-rata } \\
\text { Faktor A }\end{array}$} \\
\hline & $\mathrm{b}_{0}(100)$ & $b_{1}(80)$ & $b_{2}(60)$ & $\mathrm{b}_{3}(40)$ & \\
\hline $\mathrm{a}_{0}(0)$ & $50,00 \mathrm{a}$ & $39,33 \mathrm{a}$ & $41,3 \mathrm{a}$ & $43,67 \mathrm{a}$ & $43,58 \mathrm{~B}$ \\
\hline$a_{1}(0,93)$ & $35,33 \mathrm{a}$ & $47,67 \mathrm{a}$ & $50,67 \mathrm{a}$ & $46,33 \mathrm{a}$ & $48.33 \mathrm{AB}$ \\
\hline $\begin{array}{l}\mathrm{a}_{2}(1,86) \\
\mathrm{a}_{3}(2,80)\end{array}$ & $\begin{array}{l}68,00 \mathrm{a} \\
21,67 \mathrm{a}\end{array}$ & $\begin{array}{l}39,33 \mathrm{a} \\
37,33 \mathrm{a}\end{array}$ & $\begin{array}{l}62,67 \mathrm{a} \\
42,33 \mathrm{a}\end{array}$ & $\begin{array}{l}52,67 \mathrm{a} \\
32,67 \mathrm{a}\end{array}$ & $\begin{array}{l}55.66 \mathrm{~A} \\
33.50 \mathrm{C}\end{array}$ \\
\hline Rata-Rata Faktor B & $43.75 \mathrm{~B}$ & $40.91 \mathrm{~B}$ & $52.58 \mathrm{~A}$ & $43.83 \mathrm{~B}$ & \\
\hline
\end{tabular}

Keterangan: Faktor A dan Faktor B berbeda nyata, Faktor AxB tidak berbeda nyata angka-angka yang diikuti huruf kecil dan huruf besar pada kolom dan baris menunjukkan pengaruh yang tidak berbeda nyata pada uji DNMRT taraf 5\%.

Dari Tabel 1 dapat dilihat bahwa pemberian pupuk $\mathrm{N}$ menunjukkan pengaruh yang berbeda nyata terhadap pertambahan jumlah daun $A$. vulgaris. Pada perlakuan $\mathrm{a}_{1} \quad(0,93 \mathrm{~g})$ menunjukan 
hasil yang sama dengan perlakuan kontrol $(0 \mathrm{~g})$ dan perlakuan a2 $(1,86 \mathrm{~g})$ pemberian pupuk $\mathrm{N}$, akan tetapi pada perlakuan $\mathrm{a}_{3}(2,80 \mathrm{~g})$ terjadi penurunan pada tanaman A.vulgaris. Dari Tabel 1. Dapat disimpulkan bahwa pertambahan jumlah daun seiring dengan peningkatan dosis pupuk $\mathrm{N}$ sampai konsentrasi $1,86 \mathrm{~g} \mathrm{~N}$, pada pemberian dosis $\mathrm{N} 2,80 \mathrm{~g}$ menurunkan nilai rata-rata jumlah daun jika dibandingkan dengan kontrol.

Terjadinya peningkatan pertambahan jumlah daun seiring dengan peningkatan pemberian dosis $\mathrm{N}$ sampai batas konsentrasi 1,86 g N. Delita (2015) apabila dosis pupuk yang diberikan kurang dari kebutuhan hara tanaman Artemisia, maka hasil yang

diperoleh pun tidak optimal karena jumlah unsur -unsur hara yang dibutuhkan oleh tanaman tidak terpenuhi secara baik sehingga metabolisme dalam tubuh tanaman tidak berlangsung baik.

\section{Pertambahan Tinggi dan Panjang Akar Tanaman}

Berdasarkan analisis statistik terhadap pertambahan tinggi dan panjang akar tanaman A. vulgaris dengan pemberian pupuk $\mathrm{N}$ dan cekaman kekeringan selama 8 minggu pengamatan menunjukkan bahwa dosis pupuk $\mathrm{N}$ memberikan pengaruh yang nyata terhadap tinggi dan panjang akar tanaman sedangkan pemberian cekaman air dan interaksi antara pupuk $\mathrm{N}$ dan air tidak menunjukkan pengaruh yang beda nyata pada pertambahan tinggi dan panjang akar. Data disajikan pada Tabel 2. Tabel 2. Rata-rata tinggi dan panjang akar, tanaman Artemisia vulgaris $\mathrm{L}$. dengan perlakuan pemberian pupuk $\mathrm{N}$ setelah 8 minggu masa tanam.

\begin{tabular}{ccc}
\hline Dosis N $(\mathrm{g})$ & Pertambahan tinggi $(\mathrm{cm})$ & Panjang akar terpanjang $(\mathrm{cm})$ \\
\hline 0 & $54.6 \mathrm{a}$ & $41,3 \mathrm{~b}$ \\
0,93 & $53,0 \mathrm{a}$ & $52,0 \mathrm{a}$ \\
1,86 & $48.0 \mathrm{a}$ & $46,5 \mathrm{ab}$ \\
2,80 & $39.3 \mathrm{~b}$ & $45,0 \mathrm{ab}$ \\
\hline
\end{tabular}

Keterangan : Faktor A berbeda nyata, faktor B dan interaksi AXB tidak berbeda nyata.Data yang diikuti huruf kecil yang sama pada kolom tidak berbeda nyata pada taraf DNMRT 5\%.

Berdasarkan Tabel 2 dapat dilihat bahwa pemberian dosis pupuk $\mathrm{N}$ memberikan pengaruh yang berbeda nyata terhadap pertumbuhan tinggi tanaman A. vulgaris.Pada pemberian pupuk $\mathrm{N} \quad 0 \mathrm{~g}, \quad 0,93 \mathrm{~g}, \quad 1,86 \mathrm{~g}$ menunjukkan pengaruh yang sama pada tinggi tanaman. Sedangkan penambahan dosis 2,80 g N terjadi kecendrungan penurunan pada tinggi A.vulgaris

Pada Tabel 2. Pemberian dosis $\mathrm{N} \mathrm{0g,}$ $0,93 \mathrm{~g}, 1,86 \mathrm{~g}$ menunjukan pengaruh yang sama, hal ini diduga tanaman masih belum mengalami keterbatasan ketersediaan hara terutaman nitrogen sehingga pertumbuhannya berpengaruh sama pada setiap pemberian dosis nitrogen. Menurut Soepardi (1983) salah satu faktor lingkungan yang mempengaruhi pertumbuhan tanaman adalah ketersediaan hara dalam tanah.

Pertumbuhan tanaman akan meningkat bila unsur hara yang diberikan dalam jumlah optimal dan apabila konsentrasi ditingkatkan maka tidak akan berpengaruh terhadap pertumbuhan. Kenaikan unsur hara yang lebih lanjut dapat mengakibatkan pertumbuhan menurun (Salisbury dan Ross 1995). seperti pada pemberian dosis 2,80 N.

Pada Tabel 2. Dapat dilihat bahwa pupuk $\mathrm{N}$ berpengaruh nyata terhadap panjang akar. Pada dosis N 1,86 dan dosis 2,80 memberikan pengaruh yang sama terhadap $0,93 \mathrm{~g}$ dan $0 \mathrm{~g}$, sedangkan perlakuan $0,93 \mathrm{~g}$ dan $0 \mathrm{~g}$ memberikan pengaruh yang berbeda. Pada tabel dapat dilihat bahwa panjang akar terpanjang yaitu dengan pemberian dosis $\mathrm{N}$ 0,93 hal ini diduga bahwa pemberian dosis $\mathrm{N}$ sudah optimal untuk menunjang pertumbuhan akar tanaman A.vulgaris.

Variasi pertumbuhan pada panjang akar juga dipengaruhi oleh faktor internal dari tanaman itu sendiri seperti kondisi umur tanaman. Menurut Rajagopal (1987) salah satu faktor utama yang mempengaruhi pembentukan akar adventif yaitu pada kondisi tanaman induk. Pertambahan panjang akar dipengaruhi oleh ketersediaan unsur hara yang optimal. Salisbury dan Ross, (1995) menyatakan bahwa tanaman akan menyerap unsur hara dalam bentuk anion dan kation. Unsur hara nitrogen diserap oleh akar dalam bentuk $\mathrm{NO}_{3}{ }^{-}$(nitrat) dan $\mathrm{NH}_{4}{ }^{+}$(amonium). 
Jurnal Biologi Universitas Andalas (J. Bio. UA.)

6(2) - September 2018: 71-78 (ISSN : 2303-2162)

\section{Berat Basah Dan Berat Kering Tanaman}

Berdasarkan analisis statistik terhadap berat basah dan berat keringtanaman A. vulgaris dengan pemberian pupuk $\mathrm{N}$ dan cekaman kekeringan selama 8 minggu pengamatan menunjukkan bahwa dosis pupuk $\mathrm{N}$ memberikan pengaruh yang nyata berat basah dan kering tanaman. Data disajikan pada Tabel 3.

Tabel 3. Rata-rata berat basah dan berat keringtanaman Artemisia vulgaris.L dengan perlakuan pemberian pupuk $\mathrm{N}$ setelah 8 minggu masa tanam

\begin{tabular}{ccc}
\hline Dosis urea $(\mathrm{g})$ & Berat Basah Tanaman $(\mathrm{g})$ & Berat Kering $(\mathrm{g})$ \\
\hline 0 & $35,42 \mathrm{ab}$ & $26,01 \mathrm{~b}$ \\
0,93 & $37,96 \mathrm{ab}$ & $28,74 \mathrm{~b}$ \\
1,86 & $42,30 \mathrm{a}$ & $33,80 \mathrm{a}$ \\
2,80 & $30,33 \mathrm{~b}$ & $24,28 \mathrm{~b}$ \\
\hline
\end{tabular}

Keterangan : Faktor A berbeda nyata, faktor B dan interaksi AXB tidak berbeda nyata. Data yang diikuti huruf kecil yang sama pada kolom tidak berbeda nyata pada taraf DNMRT 5\%

Berdasarkan Tabel 3 diketahui bahwa pemberian dosis $\mathrm{N}$ pada tanaman $A$. vulgaris memberikan pengaruh yang nyata terhadap berat basah tanaman. Pada pemberian dosis $0 \mathrm{~g}$ dan $0,93 \mathrm{~g}$ menunjukkan hasil yang yang sama pada pemberian dosis 1,86 dan $2,80 \mathrm{~g} \mathrm{~N}$. Sedangkan pada pemberian dosis $1,86 \mathrm{~g}$ menunjukkan pengaruh yang berbeda dengan 2,8 g. Pada pemberian dosis $1,86 \mathrm{~N}$ yang optimal mampu menambah berat basah tanaman karna tanaman tidak kelebihan unsur hara dan tidak juga kekurangan unsur hara. Hal ini sesuai dengan pendapat Harjadi (1991) menyatakan bahwa ketersediaan unsur hara berperan penting sebagai sumber energi sehingga tingkat kecukupan hara berperan dalam mempengaruhi biomassa dari suatu tanaman, sedangkan pemberian dosis kecil tidak memberikan pengaruh yang signifikan.Menurut Sitompul dan Guritno (1995) berat basah tanaman dipengaruhi oleh kelembaban serta kadar air didalam jaringan. Menurut Sarief (1986) bahwa kandungan air didalam tanaman akan meningkat sejalan dengan peningkatan kandungan nitrogen sehingga dapat meningkatkan bobot berat basah suatu tanaman.

Pada Tabel 3. Pemberian dosis $\mathrm{N}$ juga berpengaruh terhadap berat kering tanaman. Pemberian dosis pupuk $1,86 \mathrm{~g} \mathrm{~N}$ menunjukkan hasil yang terbaik pada berat kering tanaman dan menunjukkan perbedaan yang nyata terhadap perlakuan $0 \mathrm{~g}, 0,93 \mathrm{~g}$ dan $2,80 \mathrm{~g}$ pupuk N. Hal ini diduga dari hasil penelitian yang telah dilakuan bahwa pemberian pupuk $\mathrm{N}$ meningkatkan pertumbuhan pembentukan organ vegertatif seperti daun dan juga panjang akar sehingga meningkatnya bobot kering tanaman, karna pupuk yang diberikan optimal, tidak berlebihan dan juga kekurangan. Hal ini sesuai dengan pendapat Goldsworty dan Fisher (1992) berat kering tanaman dipengaruhi oleh pertumbuhan dan pembentukan organ vegetatif. Hal yang sama dikemukakan oleh Dwijoseputro (1994) pertumbuhan organ tanaman seperti akar dan daun akan menentukan berat kering tanaman. Ditambahkan juga oleh Sarief (1986), dengan tersedianya unsur hara dalam jumlah yang cukup dan seimbang untuk pertumbuhan tanaman, menyebabkan proses pembelahan, pembesaran dan pemanjangan sel akan berlangsung cepat yang mengakibatkan beberapa organ tanaman tumbuh cepat dan tentunya akan mempengaruhi besarnya berat kering suatu tanaman.

\section{Analisis Kadar Artemisinin}

Hasil analisa kandungan artemisisnin pada tanaman A. vulgaris dengan pemberian pupuk $\mathrm{N}$ dan cekaman kekeringan dapat dilihat pada Tabel 4. 
Tabel 4. Kadar artemisinin cina baru (Artemisia vulgaris L.) dengan pemberian pupuk $\mathrm{N}$ dan cekaman kekeringan setelah 8 minggu pengamatan Kapasitas Lapang

\begin{tabular}{cc}
\hline Perlakuan & Kadar artemisinin $(\%)$ \\
\hline $\mathrm{N} 0 \mathrm{~g}+100 \%$ & 2.593721 \\
$\mathrm{~N} 0 \mathrm{~g}+80 \%$ & 0.203568 \\
$\mathrm{~N} 0 \mathrm{~g}+60 \%$ & 0.178654 \\
$\mathrm{~N} 0 \mathrm{~g}+40 \%$ & 0.05738 \\
$\mathrm{~N} 0,93 \mathrm{~g}+100 \%$ & 11.15608 \\
$\mathrm{~N} 0,93 \mathrm{~g}+80 \%$ & 0.075306 \\
$\mathrm{~N} 0,93 \mathrm{~g}+60 \%$ & 1.055418 \\
$\mathrm{~N} 0,93 \mathrm{~g}+40 \%$ & 0.056936 \\
$\mathrm{~N} 1,86 \mathrm{~g}+100 \%$ & 0.108539 \\
$\mathrm{~N} 1,86 \mathrm{~g}+80 \%$ & 11.87238 \\
N $1,86 \mathrm{~g}+60 \%$ & 0.075751 \\
N $1,86 \mathrm{~g}+40 \%$ & 0.037285 \\
N $2,80 \mathrm{~g}+100 \%$ & 0.095271 \\
N $2,80 \mathrm{~g}+80 \%$ & 0.047837 \\
N $2,80 \mathrm{~g}+60 \%$ & 0.045139 \\
N $2,80 \mathrm{~g}+40 \%$ & 0.040164 \\
\hline
\end{tabular}

Pada Tabel 4. Kandungan artemisinin pada tanaman Artemisia vulgaris didapatkan hasil, pada perlakuan cekaman kandungan artemisinin yang diperoleh cukup tinggi yaitu 11.87238 dan terendah 0.037285 . Perbedaan kandungan artemisinin yang tertinggi dan terendah sangat signifikan hal ini diduga pada pada pencuplikan kandungan artemisinin yang dilakukan akibat penggabungan semua ulangan perlakuan, sehingga kemungkinan ada satu dari perlakuan yang sangat tinggi kandungan dari artemisininnya.

Tanaman A. vulgaris hidup di area pematang sawah yang cukup bayak air hal ini diduga Metabolit sekuder dihasilkan pada perlakuan $100 \%$ KL cukup tinggi dan apabila tercekam sedikit pada $80 \%$ KL mengakibat kan kadar artemisininnya meningkat dan apabila ditingkatkan cekaman pada Artemisia akan menurun. Hal ini sesuai dengan kondisi pada penelitian yang dihasilkan Pada perlakuan pemberian $\mathrm{N} 1,86 \mathrm{~g}+80 \% \mathrm{KL}$ optimum meningkatkan kadar artemisinin pada tanaman A. vulgaris yaitu 11.87238 . Hal ini sesuai dengan penelitian yang telah dilakukan oleh Trisilawati dan Pitono (2012) dimana pembentukan bahan aktif pada purwoceng (pimpinella pruatjan) kandungan metabolit sekundernya meningkat seperti kandungan.

bahan aktif steroid, saponin dan bergapten pada keadaan tercekam, selain itu pupuk juga berpengaruh pada peningkatan kadar metabolisme tanaman.

Pada perlakuan N 1,86 g $+40 \% \mathrm{KL}$ hasil yang diperoleh kadar artemisinin yang terkecil 0.037285 hal ini diduga dipengaruhi oleh tingginya metabolisme sekunder meningkatan penurunan pada tanaman, atau sebaliknya, rendahnya kadar metabolisme juga biasa dipengaruhi oleh faktor lingkungan seperti unsur hara dan air. Apabila pasokan air terlalu banyak atau terlalu sedikit maka penyerapan tidak sempurna dan tekanan turgor meningkat pada tanaman Devies (1995). Pemupukan juga berperan penting untuk produksi biomassa tanaman. Biomassa tanaman langsung berkorelasi dengan total Artemisinin. Kebutuhan pupuk bervariasi tergantung pada kondisi dan jenis tanah serta ketersedian unsur hara didalam tanah.

\section{Kesimpulan}

Dari penelitian yang telah dilakukan mengenai pengaruh $\mathrm{N}$ dan cekaman kekeringan terhadap pertumbuhan dan kandungan artemisinin tanaman Artemisia vulgaris L. maka dapat disimpulkan bahwa, pertama, Pemberian pupuk $\mathrm{N}$ memberikan pengaruh terhadap pertambahan jumlah daun, pertambahan tinggi tanaman, panjang akar, bobot basah, dan bobot kering serta kandungan artemisinin pada pertumbuhan tanaman A.vulgaris. Kedua, Pemberian cekaman air 60\% KL memberikan pengaruh yang berbeda nyata terhadap jumlah 
K Terhadap Inseptisol dan Jagung. daun dan kadar artemisnin tertinggi diperoleh pada $80 \%$ KL pada pertumbuhan A.vulgaris. Ketiga, Pemberian pupuk $\mathrm{N}$ dan cekaman air tidak menunjukkan interaksi terhadap pertumbuhan dan kandungan artemisinin pada tanaman Artemisia vulgaris L..

\section{Ucapan Terima Kasih}

Ucapan terima kasih ditujukan kepada ibu Warnetty Munir MS yang telah memberikan izin pengambilan sampel $A$. vulgaris, bapak Dr. Chairul dan Prof Syamsuardi M.Sc yang telah memberikan kritik untuk karya tulis ilmiah. Kepada teman- teman yang telah membantu saat penelitian dan terimakasih kepada jurusan Biologi yang telah memberikan bantuan materi BAZIZ Jurusan Biologi.

\section{Daftar Pustaka}

Davies, J. P. 1995. Plant Hormone Their Nature, Occurrence and Function. In: P.J. Davies (ed.): Plant Hormones: Phisiology, Biochemistry, and Moleculer Biology. Kluwer Academic Publisher. Boston.

Delita, M. 2015. Pengaruh Pemberian Beberapa Konsentrasi Pupuk Organik Cair dari Limbah Sayur Dengan Bioaktivator MOL (Mikoorganisme lokal) HPPB Terhadap Pertumbuhan Artemisia vulgaris L. FMIPA, Universitas Andalas. Padang.

Dwijoseputro, G. 1994. Pengantar Fisiologi Tumbuhan. PT Gramedia Pustaka Utama, Jakarta.

Goldworthy, P. R. And N. M. Fisher. 1992. Fisiologi Tanaman Budidaya Tropik. Gadjah Mada Press. Yogyakarta.

Gusmaini dan Nurhayati H. 2007. Potensi Pengembangan Budidaya Artemessia annua L. di Indonesia. Balai Penelitian Tanaman Obat dan Aromatik. Bogor..

Harjadi, S. S.1991. Penghantar Agronomi. Gramedia, Jakarta

Hendra J et.al (2014) Aplikasi Kompos Ganggang Cokelat (Sargassum polycystum) Diperkaya Pupuk N, P,

Fakultas Pertanian Universitas

Sumatra Utara. Medan.

Judzentiene A dan Buzelyte J. 2006. Chemical Composition of Essential Oil of Artemisia vulgaris L. (mugwort) from Nort Lithuania, Chemija. 2006.

Klayman, D.L. 1985. Qinghaosu (Artemisinin) : an Antimalarial Drug From China. Science .L. on Nitrogen Fertilizer and Cytokinin. Paper presented at the International Conference.

Kurnia,U, Agus, F, Adimihardja, A, Dariah, A. 2006. Sifat Fisik Tanah dan Metode Analisnya. Balai besar litbang Sumberdaya Lahan Pertanian. Departemen Pertanian

Rahardjo, M. dan I. Darwati. 2000. Pengaruh Cekaman Air terhadap Produk dan Mutu Simplisia Tempuyung (Shoncus arvensis $\mathrm{L}$.

Rajgopal, V. 1987. Hormonal Regulation Of Root Delopment Under Water Stess in Hormonal Regulation of Plant and development. Martinusnij of publish. Boston

Salisbury, F. B dan C. W., Ross. 1995. Fisiologi Tumbuhan Jilid 3. Lukman, D. R. dan Sumaryono, Penerjemah. ITB. Bandung.

Sarief. S. 1986. Kesuburan dan Pemupukan Tanah Pertanian. Pustaka Bejana

Sirait M. 2007. Penuntun Fitokimia Dalam Farmasi. Bandung (ID): ITB Pr. Indonesian Medicinal Plant, Jakarta.

Sitompul, S. M. dan B. Guritno. 1995. Analisis Pertumbuhan Tanaman. Gadjah Mada University Press. Yogyakarta.

Soepardi, G.1983. Sifat dan Ciri Tanah. IPB Pers. Bogor.

Trisilawati dan Pitono. 2012. Mengenai Pengaruh Cekaman Defisit Air Terhadap Pembentukan Bahan Aktif 
Jurnal Biologi Universitas Andalas (J. Bio. UA.)

6(2) - September 2018: 71-78 (ISSN : 2303-2162)

Pada Purwoceng, Balai Penelitian

Tanaman Rempah Dan Obat. Bogor

WHO. 2004. More Than 600 Million People

Need Effective Malaria Treatment

To Prevent Unacceptably High Death. Rates.

Yudi Y et al., (2016) Pertumbuhan dan hasil bawang daun (Allium fistulosum l.) varietas linda akibat pemberian pupuk kandang ayam dan pupuk urea. Fakultas Pertanaian Universitas Bale Bandung. Bandung. 